\title{
Influence of Super Absorbent Polymer on the Mechanical Property of High Performance Concrete
}

\author{
Junhong Shan ${ }^{1, a}$,Shaowu Guo ${ }^{1}$ \\ ${ }^{1}$ Department of civil engineering, Hebei University of Engineering, 056038Handan, Hebei. P.R. China \\ ${ }^{a}$ Corresponding author
}

\begin{abstract}
The mechanical property of concrete will be effected when the SAP added in concrete. This paper study on the law of SAP content and amount of additional water which influence mechanical property of concrete. The results show that the effect of SAP on the early compressive strength of concrete is greater than the long term compressive strength. The more the amount of SAP, the greater the impact on the strength of concrete. The introduction of appropriate additional water can reduce the loss of concrete strength, and the optimum additional water content is 20 times the mass of SAP. When the SAP content is $0.1 \%$ of the mass of cement the amount of additional water diversion is 20 times he mass of SAP, the long term compressive strength of concrete is almost no decline compared with the reference concrete. In the natural curing state, the addition of $0.1 \%$ SAP can improve the long term compressive strength.
\end{abstract}

\section{Introduction}

Because of the water cement ratio of the high performance concrete is relatively low lead to lack of free water, and the early strength of high performance concrete is rapidly increasing, resulting in the rapid consumption of free water ${ }^{[1]}$. These two aspects make cementitious material in the process of hydration make the concrete shrinkage and shrinkage deformation in the early curing stage $\mathrm{e}^{[2]}$. The shrinkage deformation of concrete will be limited, which will lead to shrinkage stress, when the stress is greater than the tensile strength of concrete, it will lead to concrete cracking, and then the performance of the concrete will be significantly reduced $^{[3]}$. Because of the high performance concrete structure is dense, external curing water extremely difficult to penetrate into the concrete, provide free water for the hydration of cementitious materials, so the traditional method of external curing for high performance concrete is difficult to achieve a good curing effect $^{[4]}$. The experts introduce the concept of internal curing. Internal curing is introduce water absorbing material in concrete which can provide the required water for the hydration of cementitious materials. The researchers found that the free water can be increased by internal curing, so it can increase the cement hydration degree, the self shrinkage and shrinkage cracking of high performance concrete can be significant reduce ${ }^{[5]}$. Super Absorbent Polymer (SAP) is a new type of Internal curing material. A little amount of SAP is needed. Not only can slove the self shrinkage and shrinkage cracking of concrete, but also will not affect the durability of concrete $^{[6]}$, but will have a certain impact on the mechanical property. In this experiment, the mechanical property of concrete in different SAP content and the amount of additional water were studied.

\section{Test method and material}

\subsection{Material}

Cement using $\mathrm{P} \bullet \mathrm{O} 42.5$ grade cement.
Coarse aggregate using $5 \sim 25 \mathrm{~mm}$ continuous gradation of natural crushed stone.

Fine aggregate using the sand in the second area of the natural river sand.

This experiment selected SAP fineness is $160-200$ mesh, with high water absorption capacity. Before the water absorption, SAP was in a state of white powder, after water absorption, SAP expanded into a colloid, rich in elasticity, with excellent water retention properties.

HSN Naphthalene series water reducer.

Using Set Retarder。

\subsection{Test method}

Adopt the method of dry mixed with SAP. When mixing concrete, put SAP and cement, sand, stone and admixture together in the concrete mixer, dry mix make the SAP particles and cement mixing, before adding water. Mixing time can be increased appropriately, so that the SAP particles can be mixed with the cementitious materials more fully. In the concrete mixing room, temperature is set at $25^{\circ} \mathrm{C}$. Using Standard curing and natural curing. In the standard curing room, the temperature is set at $20+2^{\circ} \mathrm{C}$, the relative humidity is more than $95 \%$. The curing time was 3 days, 7 days and 28 days. According to the requirements of JGJ 55 - 2011 "highway engineering cement and cement concrete test procedure", the strength of concrete is determined.

\section{Concrete mix design}

According to JGJ 55 - 2011 "common concrete mix proportion design code", the concrete mix design shown in Table 1. Specific experimental programs are shown in Table 2.

Table1 The mix design

\begin{tabular}{lll}
\hline $\mathrm{C} /\left(\mathrm{Kg} / \mathrm{m}^{3}\right)$ & $\mathrm{S} /\left(\mathrm{Kg} / \mathrm{m}^{3}\right)$ & $\mathrm{G} /\left(\mathrm{Kg} / \mathrm{m}^{3}\right)$ \\
\hline 480 & 709.5 & 1107 \\
\hline $\mathrm{W} /\left(\mathrm{Kg} / \mathrm{m}^{3}\right)$ & $\mathrm{HSN}$ & Retarder $/\left(\mathrm{Kg} / \mathrm{m}^{3}\right)$ \\
\hline 153.6 & 4.8 & 0.48 \\
\hline
\end{tabular}


The content of SAP is $0.1 \%, 0.2 \%$ and $0.3 \%$, which is the mass of cementitious materials. Amount of additional water is 10 times, 15 times, 20 times, 25 times, and 30 times the mass of SAP.

Table2 Scheme of test

\begin{tabular}{|c|c|c|c|c|c|}
\hline Number & $\begin{array}{c}\text { SAP } \\
\text { content }\end{array}$ & $\begin{array}{c}\text { Additional } \\
\text { water }\end{array}$ & Number & $\begin{array}{c}\text { SAP } \\
\text { content }\end{array}$ & $\begin{array}{c}\text { Additional } \\
\text { water }\end{array}$ \\
\hline $\mathrm{A}_{1}-01$ & 0 & 0 & $\mathrm{~A}_{3}-04$ & $0.2 \%$ & 20 \\
\hline $\mathrm{A}_{2}-01$ & $0.1 \%$ & 0 & $\mathrm{~A}_{3}-05$ & $0.2 \%$ & 25 \\
\hline $\mathrm{A}_{2}-02$ & $0.1 \%$ & 10 & $\mathrm{~A}_{3}-06$ & $0.2 \%$ & 30 \\
\hline $\mathrm{A}_{2}-03$ & $0.1 \%$ & 15 & $\mathrm{~A}_{4}-01$ & $0.3 \%$ & 0 \\
\hline $\mathrm{A}_{2}-04$ & $0.1 \%$ & 20 & $\mathrm{~A}_{4}-02$ & $0.3 \%$ & 10 \\
\hline $\mathrm{A}_{2}-05$ & $0.1 \%$ & 25 & $\mathrm{~A}_{4}-03$ & $0.3 \%$ & 15 \\
\hline $\mathrm{A}_{2}-06$ & $0.1 \%$ & 30 & $\mathrm{~A}_{4}-04$ & $0.3 \%$ & 20 \\
\hline $\mathrm{A}_{3}-01$ & $0.2 \%$ & 0 & $\mathrm{~A}_{4}-05$ & $0.3 \%$ & 25 \\
\hline $\mathrm{A}_{3}-02$ & $0.2 \%$ & 10 & $\mathrm{~A}_{4}-06$ & $0.3 \%$ & 30 \\
\hline $\mathrm{A}_{3}-03$ & $0.2 \%$ & 15 & & & \\
\hline
\end{tabular}

\section{Test result and analysis}

\subsection{Test result}

The test results are shown in Table 3 .

Table3 Compressive strength(standard curing)

\begin{tabular}{|c|c|c|c|}
\hline \multirow{2}{*}{ Number } & \multicolumn{3}{|c|}{ Compressive strength } \\
\cline { 2 - 4 } & $3 \mathrm{~d}$ & $7 \mathrm{~d}$ & $28 \mathrm{~d}$ \\
\hline $\mathrm{A}_{1}-01$ & 45.48 & 55.74 & 66.89 \\
\hline $\mathrm{A}_{2}-01$ & 40.32 & 52.21 & 64.03 \\
\hline $\mathrm{A}_{2}-02$ & 39.13 & 51.62 & 64.20 \\
\hline $\mathrm{A}_{2}-03$ & 39.89 & 52.78 & 65.16 \\
\hline $\mathrm{A}_{2}-04$ & 40.21 & 53.42 & 66.78 \\
\hline $\mathrm{A}_{2}-05$ & 39.24 & 52.68 & 65.83 \\
\hline $\mathrm{A}_{2}-06$ & 37.73 & 51.66 & 65.19 \\
\hline $\mathrm{A}_{3}-01$ & 36.09 & 50.44 & 62.29 \\
\hline $\mathrm{A}_{3}-02$ & 34.05 & 48.46 & 61.84 \\
\hline $\mathrm{A}_{3}-03$ & 34.38 & 49.79 & 62.24 \\
\hline $\mathrm{A}_{3}-04$ & 34.13 & 50.95 & 63.78 \\
\hline $\mathrm{A}_{3}-05$ & 33.09 & 49.92 & 62.36 \\
\hline $\mathrm{A}_{3}-06$ & 31.87 & 48.45 & 60.68 \\
\hline $\mathrm{A}_{4}-01$ & 32.76 & 48.81 & 60.11 \\
\hline $\mathrm{A}_{4}-02$ & 31.47 & 46.50 & 59.69 \\
\hline $\mathrm{A}_{4}-03$ & 30.88 & 46.61 & 59.16 \\
\hline $\mathrm{A}_{4}-04$ & 29.17 & 46.47 & 58.35 \\
\hline $\mathrm{A}_{4}-05$ & 27.29 & 45.41 & 56.82 \\
\hline $\mathrm{A}_{4}-06$ & 25.18 & 44.58 & 55.11 \\
\hline
\end{tabular}

Table4 Compressive strength(natural curing)

\begin{tabular}{|c|c|c|c|}
\hline \multirow{2}{*}{ number } & \multicolumn{3}{|c|}{ Compressive strength } \\
\cline { 2 - 4 } & $3 \mathrm{~d}$ & $7 \mathrm{~d}$ & $28 \mathrm{~d}$ \\
\hline $\mathrm{A}_{1}-01$ & 40.29 & 50.72 & 61.91 \\
\hline $\mathrm{A}_{2}-01$ & 38.48 & 48.06 & 62.20 \\
\hline $\mathrm{A}_{2}-02$ & 34.25 & 45.39 & 61.67 \\
\hline $\mathrm{A}_{2}-03$ & 35.47 & 45.84 & 62.47 \\
\hline $\mathrm{A}_{2}-04$ & 36.93 & 47.65 & 62.93 \\
\hline $\mathrm{A}_{2}-05$ & 34.66 & 45.81 & 61.96 \\
\hline $\mathrm{A}_{2}-06$ & 31.76 & 42.48 & 61.67 \\
\hline $\mathrm{A}_{3}-01$ & 35.96 & 47.58 & 59.29 \\
\hline $\mathrm{A}_{3}-02$ & 32.18 & 44.27 & 59.60 \\
\hline $\mathrm{A}_{3}-03$ & 33.71 & 46.02 & 60.58 \\
\hline $\mathrm{A}_{3}-04$ & 34.80 & 47.32 & 59.97 \\
\hline $\mathrm{A}_{3}-05$ & 33.19 & 45.72 & 58.89 \\
\hline $\mathrm{A}_{3}-06$ & 31.06 & 43.53 & 58.63 \\
\hline $\mathrm{A}_{4}-01$ & 31.16 & 44.11 & 56.18 \\
\hline $\mathrm{A}_{4}-02$ & 27.81 & 40.64 & 53.87 \\
\hline $\mathrm{A}_{4}-03$ & 29.24 & 42.18 & 55.03 \\
\hline $\mathrm{A}_{4}-04$ & 30.37 & 43.55 & 55.49 \\
\hline $\mathrm{A}_{4}-05$ & 28.76 & 41.60 & 54.86 \\
\hline $\mathrm{A}_{4}-06$ & 26.68 & 39.89 & 53.74 \\
\hline
\end{tabular}

\subsection{Effect of SAP content}

From table 3, the results show that the early strength of concrete have a great loss after introducing the SAP. As shown in Figure 1, when the additional water is not introduced, the strength of concrete is reduced greater when the SAP content is multiple. The influence of SAP on the early strength is more than the influence of the long-term strength. As shown in Figure 2, 3 and 4, the concrete doped with different amounts of SAP, the change of concrete strength will have similar rules when introduce additional water in concrete.

The reason for this situation is that the SAP has extremely strong water absorption. After the introduction of SAP, the water is absorbed, so that the free water in the cement paste is reduced, which hinders the early hydration of cement, and the SAP is the second phase of low strength in concrete ${ }^{[7]}$. So the early strength of concrete will have a big loss. With the increase of curing time, SAP particles will release water into cement paste, increase the amount of free water in the cement paste, and then promote the hydration reaction of cement, the concrete strength will be improved quickly, so the loss of 28d strength will be less than 3d strength. But when the SAP is no longer contains water, the particles go back to the dry state, will leave honeycomb holes in the paste ${ }^{[8]}$, which reduce the effective area of the specimens. When the specimen are compressed, the holes will produce stress concentration may cause further damage to the internal structure of concrete. So it will decrease the compressive strength of concrete. The amount of SAP is added, the worse the mechanical properties of the concrete, which is due to the SAP is the second phase of low strength in concrete. At the same time, because of the increase of SAP content, there are more pores in the paste, which increase the porosity, further reduce the effective area of the specimen, and intensified the stress concentration, Thereby exacerbating the loss of compressive strength of concrete. 


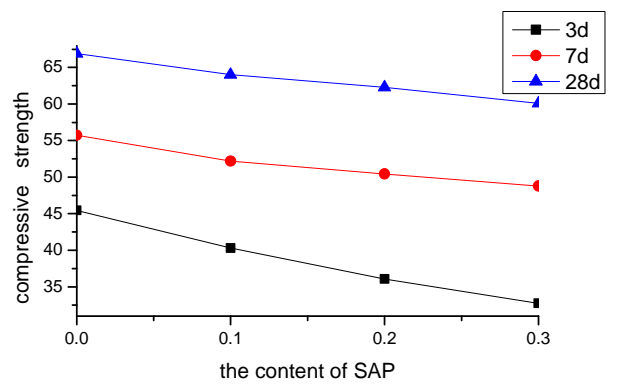

Figure 1. The effect of SAP content on concrete strength (standard curing, no additional water)

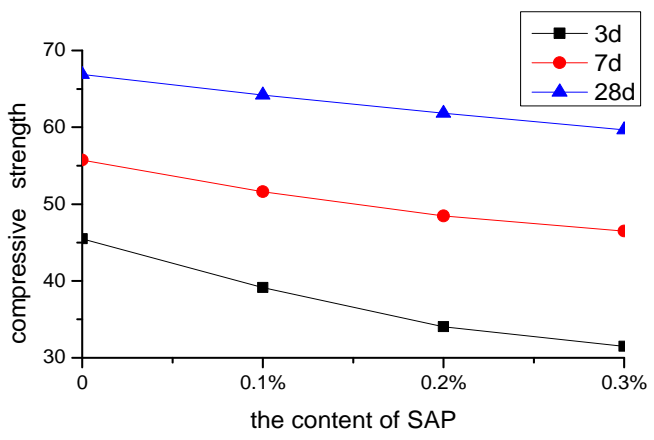

Figure 2. The effect of SAP content on concrete strength (standard curing, add 10 times additional water)

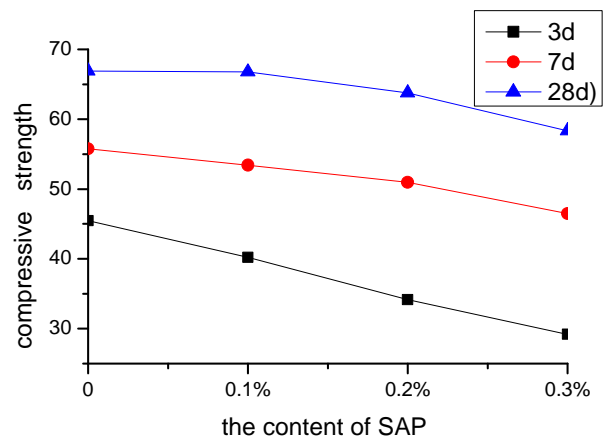

Figure3 the effect of SAP content on concrete strength (standard curing, add 20 times additional water)

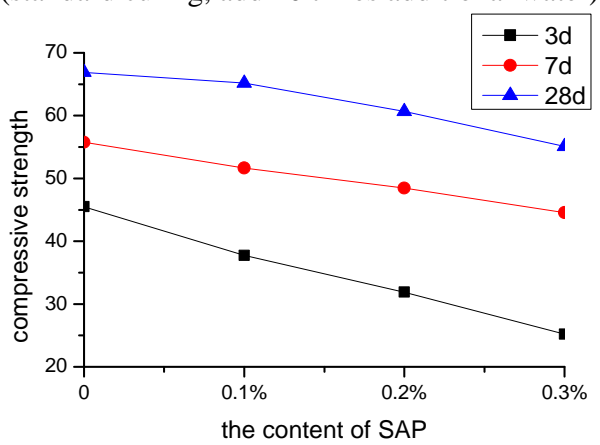

Figure4 the effect of SAP content on concrete strength (standard curing, add 30 times additional water)

\subsection{Effect of additional water content}

When adding $0.1 \%$ SAP the mass of cement, introduce additional water can slightly improve the 28d strength of concrete, as shown in Figure 5. With the increase of water diversion, the 28d strength of concrete is increased, and the 28d compressive strength of the specimen $\left(\mathrm{A}_{2}-04\right)$ reaches a peak value when the amount of additional water is 20 times the mass of SAP, compared with the reference concrete. While the 28d strength will be reduced gradually when the water content is more than 20 times. It can be known that, with a certain amount of SAP and the additional water, the introduction of SAP will not lead to the decrease of the long-term strength. As shown in figure $5,6,7$, When the additional water content is 20 times the mass of SAP, the 28d compressive strength of concrete reaches the highest value.

Adding additional water will significantly reduce the $3 d$ strength when the concrete is added plentiful SAP. When the SAP content is $0.2 \%$ the mass of cement, the change of the additional water content will not affect the 28d strength of the concrete. When the SAP content is $0.3 \%$ the mass of the cement, introducing additional water will make the 28d strength decreased significantly. When the additional water content is more than 20 times the mass of SAP, the 28d strength of the concrete will be severe decline. When the SAP content is $0.3 \%$ the mass of the cement, the additional water amount is 30 times the mass of $\mathrm{SAP}\left(\mathrm{A}_{4}-06\right)$, the $28 \mathrm{~d}$ compressive strength of concrete decreased by $17.6 \%$. This shows that if the content of SAP is overmuch or the additional water is excessive, the strength of concrete will be significantly reduced.

When introduce additional water in concrete, the early strength is reduced, because the introduction of additional water makes the free water increased, the water cement ratio is improved, which leads to the decrease of the strength of the concrete. On the other hand, the introduction of additional water increase the free water in the concrete, promote the hydration process of cement, which promotes the development of concrete strength, and therefore improves the long-term strength of the concrete. But when the amount of additional water is excessive, the water cement ratio of concrete is obviously improved, which reduces the strength of concrete.

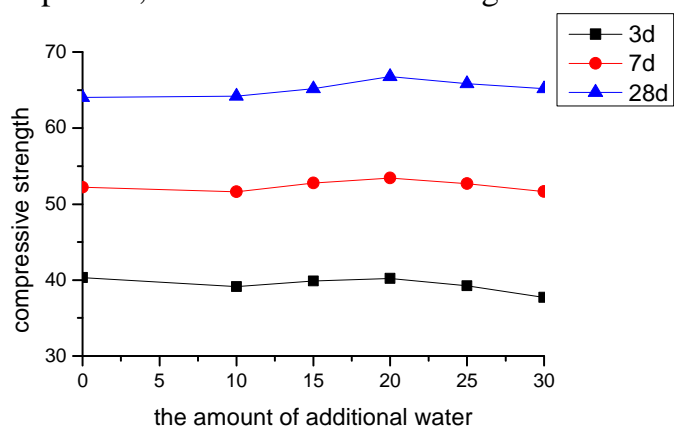

Figure5 The amount of additional water that effect the strength of concrete (standard curing condition, SAP content is $0.1 \%$ ) 


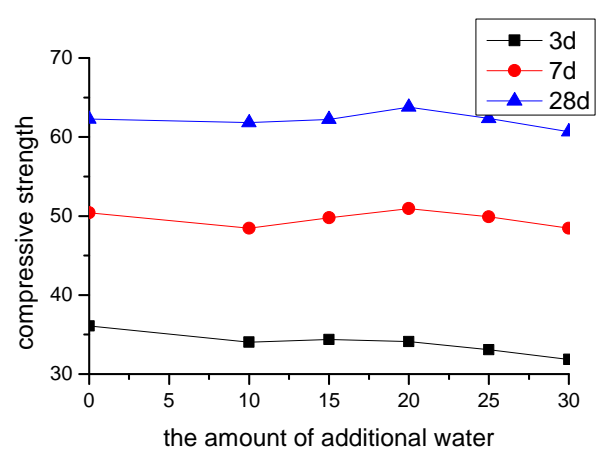

Figure6 The amount of additional water that effect the strength of concrete (standard curing condition, SAP content is $0.2 \%$ )

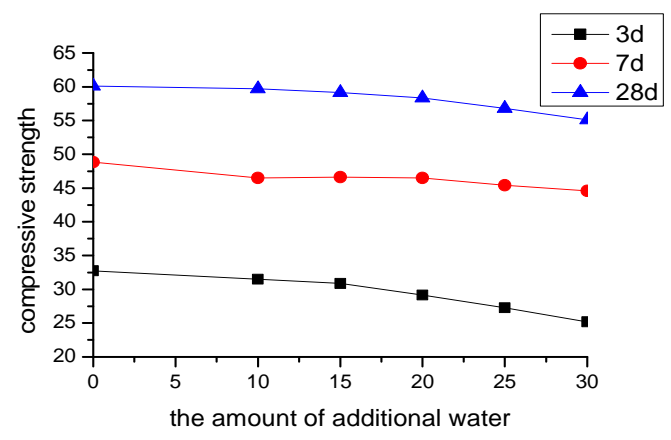

Figure7 The amount of additional water that effect the strength of concrete (standard curing condition, SAP content is $0.3 \%$ )

\subsection{Effect of different curing methods}

In the natural curing condition, the influence of SAP content and the amount of additional water on the strength is similar than the standard curing condition. As shown in Table4, The 28d strength of specimen $\mathrm{A}_{2}-01$ is slightly higher than specimen $\mathrm{A}_{1}-01$, which shows that SAP has a good effect on internal curing of concrete, that in the natural curing condition, the relative humidity of concrete is lower, and it can't effectively replenish the water consumption of cement hydration, while the internal curing can provide free water to promote cement hydration, so the concrete strength can be improved. Compared to the standard curing condition, the 28d strength of the natural curing group has been reduced that shown in the Table3,4, which indicates that although the SAP can provide internal curing of the concrete, the External curing is still needed. Therefore, in the site operation, blending internal curing with appropriate external maintenance, can achieve a better maintenance effect.

\section{Conclusion}

The early strength of concrete will be reduced when adding SAP in concrete, but with the increase of curing time, the SAP particles can release water, the increase of free water can promote the hydration reaction of cement, which makes the concrete strength develop quickly, so the impact of the SAP on long-term strength is smaller than early strength. The more the SAP content, the greater the loss of strength of concrete.
When introduce the SAP in concrete, the appropriate introduction of additional water can reduce the loss of 28d strength of concrete. When the content of SAP and the amount of additional water are appropriate $\left(\mathrm{A}_{2}-04\right)$, the 28d strength of the concrete will be almost no decrease. But if the content of SAP is too much or the amount of additional water is excessive (A4-06), the concrete strength will have a significant loss. The optimal SAP content was $0.1 \%$ the mass of the cement. When introduce 15 times additional water, the flexural strength reached the highest value. When introduce 20 times additional water, the compressive strength reached the highest value.

In the site operation, introducing SAP in the high performance concrete, with appropriate external maintenance, curing effec of the high performance concrete can be significantly improved.

\section{References}

[1] F.Z.Wang, Y.F.Zhou, Z.C.Liu. Autogenous shrinkage of conference with super-absorbent polymer. J. ACI Materials Journal, 2009, 106(2), pp973-978.

[2] A.S.Eldieb. elf-curing Concrete: Water Retention, Bydration and Moisture Transport. J. Construction and Builiding Materials, 2007, 21(6), pp1282-1287.

[3] D.Cusson, T.Hoogeveen. Internal Curing of HighPerformance Concrete with Pre-soaked Fine Lightweight Aggregate for Prevention of Autogenous Shrinkage Cracking. J. Cement and Concrete Research, 2009, 38, pp757-765.

[4] J. Piérard, V. Piérard, N. Piérard. Mitigition of autogwnuos Shrinkage in HPC by Intenational Curing Using Superabsorbent Polymers. J. Belgian Building Res Inst, 2008, 9, pp97.

[5] B.Craeye. Reduction of Autogenous Shrinkage of Concrete by Means of Internal Curing. D. Ghent University, 2006.

[6] B.Craeve, M.Geirnaer, G.M.Geirnae. Super Absorbing Polymers as an International Curing Agent for Mitigation of Early-age Cracking of High - Performance Concrete Bridge Decks. J. Conster Buliding Master, 2011, 25, pp1-3.

[7] L.F.Pang, S.Y.Run, Y.T.Cai. Effects of Internal Curing by Super Absorbent Polymer on Shrinkage of Concrete. J. Key Engineering Materials, 2011, 477, pp200-204.

[8] L.F.Peng, Y.T.Cai, Q.S.Chang. The study on the properties of super absorbent polymer in expansive concrete. J. Advanced Materials Research, 2011, 194, pp1138-1142. 